\title{
Low Density Polyethylene (LDPE) blends based on Poly(3-Hydroxi-Butyrate) (PHB) and Guar Gum (GG) biodegradable polymers
}

\author{
Marisa Cristina Guimarães Rocha ${ }^{1 *}$ and Lorena Rodrigues da Costa Moraes ${ }^{1}$ \\ 'Instituto Politécnico, Universidade do Estado do Rio de Janeiro - UERJ, Nova Friburgo, RJ, Brasil \\ *mrocha@iprj.uerj.br
}

\begin{abstract}
LDPE blends based on PHB and GG biodegradable polymers were prepared by melt mixing in a twin screw extruder. The mechanical properties of the materials were evaluated. Preliminary information about the biodegradation behavior of the specimens was obtained by visual observation of samples removed from the simulated soil in 90 days. The results indicated that LDPE/PHB blends may be used for designing LDPE based materials with increased susceptibility to degradation, if elongation at break and impact properties are not determinant factors of their performance. LDPE based materials on GG present values of flexural and mechanical strength lower than those of LDPE/PHB blends. LDPE/PHB/GG blends exhibit unsatisfactory properties. Apparently, the effect of addition of GG to LDPE on the biodegradation behavior of LDPE/GG blends was less intense than the effect caused by addition of PHB to the blends. Similar observation has occurred with the partial replacement of GG by PHB in the ternary blends.
\end{abstract}

Keywords: blends, guar gum, low density polyethylene, mechanical properties, poly (3-hydroxi-butyrate).

\section{Introduction}

The industry of polyolefins is still a very dynamic business where low density polyethylene (LDPE) plays a key role due to its wide range of applications. This polymer has good properties, such as: high flexibility, good processability, excellent resistance to dilute and concentrated acids, alcohols, bases and esters, impact resistance and dimensional stability. However, the use of this polymer causes serious environmental concerns because it is a bioinert polymer, which means that it is highly resistant to assimilation by microorganisms, such as fungi and bacteria ${ }^{[1,2]}$.

Recycling is considered an alternative to reduce the adverse environmental impact associated with the plastic waste, but some artifacts may not be recycled and, in some cases, this process is not economically viable. In this scenario, studies have been conducted in order to develop, at least, partially biodegradable plastics by blending the fossil-fuel-based conventional polymers with biodegradable polymers, such as starch or cellulose. There are evidences that the degradability of LDPE has been improved when native starch or thermoplastic starch is added to it, although the pure LDPE is not biodegradable ${ }^{[1-4]}$.

Poly (3-hydroxybutyrate) (PHB) is aliphatic polyester produced by several microorganisms that presents very good mechanical properties. In the last decades PHB has attracted much interest in medical and agricultural applications owing to its biocompatibility and biodegradability. An approach to increase polyethylene biodegradability involves its blend with PHB. It is believed that in the case of PHB based blends containing a non-biodegradable fossil-fuel-conventional polymer, a kind of "biodeterioration" may occur according to the morphology and surface properties of the samples.
As a matter of fact, the microorganisms attack to the PHB part of the whole samples causes a disintegration of the whole samples by subtracting cementing material between separate synthetic regions. Therefore, the addition of PHB to conventional thermoplastics can be used to reduce the huge amount of packaging wastes in landfills ${ }^{[5-13]}$.

There are few papers published concerning the biodegradation properties of the LDPE/PHB blends. According to Martelli et al. ${ }^{[5]}$, the literature for this type of blend is very modest mainly regarding blends of polyethylene/PHB without pro-oxidants.

A previous work ${ }^{[6]}$ demonstrated that although the addition of PHB to LDPE causes the deterioration of some mechanical properties, blends with tensile strength values in the range from 8.9 to $10 \mathrm{MPa}$ can be obtained. As some commercial grades of LDPE have mechanical strength in this range, it was inferred that the addition of a certain amount of PHB to LDPE may be considered as a possibility for obtaining LDPE based materials with increased susceptibility to biodegradation. The results of this work also indicated that castor oil cake, hydrophilic filler, may accelerate the degradation of LDPE/PHB blends.

Galactomannans are neutral polysaccharides composed of a linear mannose long chain bearing side chains with a single galactose unit. According to the botanic origin, their structure i.e. molecular weight, the ratio mannose (M) / galactose (G) and the distribution of galactose units in the galactomannans backbone will be different. The two major galactomannans exploited commercially are guar gum (GG) and locust bean gum (LGB). These polyssacharides differ primarily in terms of their content of galactose. Guar galactomannan contains around 39\% of 
galactose whereas locust bean gum has a galactose content of about $23 \%$. As a consequence of its lower content of galactose, locust bean is less soluble in water than guar $\operatorname{gum}^{[14,15]}$.

Galactomannans present a wide range of food applications due to their ability to form very viscous solutions at low concentrations. They also have been used for other industrial purposes related to pharmaceutical and $\operatorname{cosmetics}^{[16,17]}$.

Guar gum is a cheap polymer, produced in abundance and easily available from many renewable sources. Therefore, the development of biodegradable films based on guar gum has been subject of several studies. Chemical modification or blending of guar gum with other polymers has been pointed as an approach to reduce its poor flexibility and high moisture sensitivity ${ }^{[18-20]}$.

The possility of adding galactomanns to LDPE in order to enhance the susceptibility of LDPE based materials to biodegradation has not been evaluated, yet. There is a lack of studies on polyethylene blends based on galactomananns.

Skalkova et al. ${ }^{[20]}$ prepared LDPE blends based on LGB galactomannan. The effect of the addition of the compatibilizer agent, ethylene-acid acrylic copolymer (EAA), on the morphology, viscoelastic behavior and thermal properties of the blends was evaluated. It was found that the addition of LGB to LDPE causes a reduction of the LDPE storage modulus ( $\left.\mathrm{E}^{\prime}\right)$, and that the addition of EAA to the blends has a positive effect on $\mathrm{E}^{\prime}$. It was also verified that a more homogeneous and finer morphology is obtained with the addition of EAA to the blends.

The aim of this study is to evaluate the mechanical behavior of LDPE/PHB, LDPE/GG and LDPE/PHB/GG blends and to make a preliminary investigation about their biodegradation behavior of these blends in simulated soil.

\section{Experimental Procedure}

\subsection{Materials}

Low density polyethylene (LDPE, TS 0728), $\mathrm{MFI}=2.20 \mathrm{~g} / 10 \mathrm{~min}-\mathrm{ASTM} \mathrm{D} 1238$, at $190^{\circ} \mathrm{C}$ was donated by Petroquímica Triunfo (Brazil) and used as received. Poly (3-hydroxybutyrate) (PHB), MFI= $16 \mathrm{~g} / 10 \mathrm{~min}$ - ASTM D 1238 , at $190^{\circ} \mathrm{C}$ was obtained from PHB Industrial and used as received. Guar gum was donated by Farmos Comércio e Indústria Ltda and used as received.

\subsection{Blends processing and characterization}

LDPE/ PHB / GG blends were prepared in a twin screw extruder (Extrusão Brasil- Model DRC) with $22 \mathrm{~mm}$ diameter screw extruder and a length to diameter (L/D) ratio equal to 36 , at $100 \mathrm{rpm}$. The composition of the blends is presented in Table 1. The temperature profile in the extruder from the feed to the metering zone was set at $90 / 140 / 140 / 140 / 140^{\circ} \mathrm{C}$.

Melt flow index (MFI) values of the materials were determined following ASTM D 1238 using a Tinius-Olsen Extrusion Plastometer Model MP993.
Table 1. Composition of LLDPE/PHB/GG blends

\begin{tabular}{ccccccc}
\hline & \multicolumn{2}{c}{ LDPE } & \multicolumn{2}{c}{ PHB } & \multicolumn{2}{c}{ GG } \\
\hline $\begin{array}{c}\text { Sample } \\
\text { code }\end{array}$ & $\%$ & grams & $\%$ & grams & $\%$ & Grams \\
\hline 1 & 70 & 350 & 30 & 150 & 0 & 0 \\
2 & 70 & 350 & 0 & 0 & 30 & 150 \\
3 & 70 & 350 & 25 & 125 & 5 & 25 \\
4 & 70 & 350 & 20 & 100 & 10 & 50 \\
5 & 70 & 350 & 15 & 75 & 15 & 75 \\
6 & 70 & 350 & 10 & 50 & 20 & 100 \\
7 & 70 & 350 & 5 & 25 & 25 & 125 \\
8 & 100 & 500 & 0 & 0 & 0 & 0 \\
9 & 0 & 0 & 100 & 500 & 0 & 0 \\
\hline
\end{tabular}

Tensile properties were measured using a Shimadzu Universal Testing Machine, Model AG-I with a $5 \mathrm{KN}$ load cell. Tests were conducted in accordance with ASTM D 638 using Type $\mathrm{V}$ test specimen dimensions. A crosshead speed of $10 \mathrm{~mm} / \mathrm{min}$ was employed. The flexural tests were carried on a Shimadzu Universal Testing Machine based on ASTM D-790. Tests were conducted at cross head speed of $10 \mathrm{~mm} / \mathrm{min}$ at $23^{\circ} \mathrm{C}$.

Izod impact tests were performed using a $36.98 \mathrm{~N}$ pendulum on a Tinius- Olsen Impact Tester based on ASTM D-256.

\subsection{Simulated soil biodegradation experiment}

The simulated soil consisted of $23 \%$ loamy silt, $23 \%$ organic matter (cow manure), $23 \%$ sand and $31 \%$ water (all w/w). The soil $\mathrm{pH}$, equal to 7 , was determined using the digital $\mathrm{pH}$ meter Model PHS-3B PHtek. Five type I specimens prepared according to ASTM D-638 were weighed and buried in simulated soil under atmospheric conditions. After 90 days, the buried samples were recovered, washed with water and dried. Preliminary information about the biodegradation behavior of the blends was inferred from observation of the visual appearance of the LDPE blends specimens, which were registered in photographs.

\section{Results and Discussion}

It is well known that PHB has a narrow processing window. Therefore, a factorial design was used in order to define the processing conditions of PHB in the twin screw extruder. Temperature and screw rotation were the entrance variables and melt flow index was the response variable. It was verified that the temperature is the most significant variable. The increase of temperature promotes the PHB degradation. It was also observed that there is an interaction effect between temperature and screw rotation. A combination of low screw rotation and high temperatures promotes the degradation of PHB due to the increase of the residence time of the material in the extruder. The MFI values of PHB in different experimental conditions are presented in Table 2

Based on these results, the process conditions adopted for the pure polymers and for the LDPE blends in the extruder were: temperature profile from the feed to the 
metering zone equal to $90 / 140 / 140 / 140 / 140^{\circ} \mathrm{C}$ and screw rotation equal to $100 \mathrm{rpm}$ These experimental conditions provide a MFI value of PHB closer to one furnished by the PHB supplier (MFI=16). Table 2 also shows that these conditions are adequate for processing LDPE (MFI=2.1), that apparently is not modified by degradation or crosslinking reactions. The MFI values of LDPE, PHB and LDPE/PHB/GG blends processed in the extruder using the established experimental conditions are presented in Table 3.

Melt flow index (MFI) is an empirically defined parameter, inversely proportional to the melt viscosity at a temperature and shear rate specified by the operating conditions of measurement. Although it is not a fundamental property of a polymer, this parameter has been widely used in the industry in order to characterize the flow properties of the polymers ${ }^{[21]}$.

The inspection of Table 3 shows that as the content of guar gum in the blends increases, the MFI decreases. It is well known that guar gum has a high shear viscosity, and then this result was expected. However, the MFI results show that 70/30 LDPE/GG blend presents good processing properties in the experimental conditions used in this work. Table 3 also shows that the MFI of the blends increases as the content of PHB in the blends increases. The MFI value of PHB is too high, so this result was also expected.

Tensile properties were determined in order to give some indication of the balance of the properties achieved with the various blends.

The tensile properties of the materials are presented in Table 4

Table 2. Melt flow index (MFI) of PHB in several experimental conditions.

\begin{tabular}{cccc}
\hline Material & Temperature $\left({ }^{\circ} \mathbf{C}\right)$ & $\begin{array}{c}\text { Screws } \\
\text { Rotation } \\
(\mathbf{r p m})\end{array}$ & $\begin{array}{c}\text { MFI } \\
(\mathbf{g} / \mathbf{1 0 m i n})\end{array}$ \\
\hline PHB & $80 / 155 / 160 / 170$ & 150 & 262.8 \\
PHB & $80 / 155 / 160 / 160$ & 150 & 87.3 \\
PHB & $80 / 150 / 150 / 150$ & 150 & 51.4 \\
PHB & $80 / 155 / 160 / 160$ & 100 & 54.4 \\
PHB & $80 / 150 / 150 / 150$ & 100 & 28.3 \\
PHB & $90 / 140 / 140 / 140$ & 100 & 21.2 \\
PHB & $80 / 155 / 160 / 160$ & 50 & 112.4 \\
PHB & $80 / 150 / 150 / 150$ & 50 & 29.1 \\
LDPE & $90 / 140 / 140 / 140$ & 100 & 2.1 \\
\hline
\end{tabular}

Table 3. Melt Flow Index (MFI).

\begin{tabular}{llll}
\hline \multicolumn{1}{c}{ Blends } & \multicolumn{1}{c}{ MFI (g/10min) } & Error \\
\hline PHB (100) & 21.2 & 2.0 \\
LDPE (100) & 2.1 & 0.2 \\
LDPE/PHB (70/30) & 5.1 & 0.5 \\
LDPE/GG (70/30) & 1.2 & 0.1 \\
LDPE/PHB/GG (70/25/5) & 5.0 & 0.5 \\
LDPE/PHB/GG (70/20/10) & 4.9 & 0.3 \\
LDPE/PHB/GG (70/15/15) & 4.8 & 0.5 \\
LDPE/PHB/GG (70/10/20) & 1.9 & 0.2 \\
LDPE/PHB/GG (70/5/25) & 1.7 & 0.1 \\
\hline
\end{tabular}

The analysis of Table 4 demonstrates that the Young Modulus of PHB is much higher than the tensile modulus of LDPE. PHB is considered a hard and brittle material. The brittleness of PHB is related to the following factors: Secondary crystallization of the amorphous phase during the storage time at room temperature, leading to a fast decreasing of elongation at break; glass transition temperature ( $\mathrm{Tg}$ ) close to the room temperature and low nucleation density which generates large spherulites and cracks between them ${ }^{[6]}$. On the other hand, LDPE is a flexible material. Therefore, the addition of PHB to LDPE causes an increase of the tensile modulus of LDPE.

The value of tensile modulus of the binary LDPE/GG blend shows that addition of GG to LDPE leads to an increase of the elastic modulus of LDPE. This result was expected. The Young's modulus is a measure of bonding forces and guar gum presents strong intermolecular bonds (hydrogen bonds). The results also show that increase of LDPE modulus due to the addition of PHB is higher than the effect promoted by the GG addition to this polyolefin.

Table 4 shows that the ternary blends also present higher tensile modulus than LDPE. The results also show that considering the Young Modulus of the binary LDPE/PHB blend as reference, the partial replacement of PHB for GG in ternary blends leads to a decrease of the tensile modulus.

PHB has a tensile strength value (25.4 MPa) higher than the one presented by LDPE (12.2 MPa). Table 4 and Figure 1 show that the addition of PHB to LDPE causes a reduction in the strength of this polymer. Similar results have been reported in literature and they have been attributed to the immiscibility of LDPE/PHB blends and the weak interfacial adhesion between the two polymers ${ }^{[6]}$. However, it may be emphasized that the tensile strength value of the 70/30 LDPE/PHB blend $(9.1 \mathrm{MPa})$ is quite similar to the values presented by some grades of $\mathrm{LDPE}^{[22]}$.

The addition of guar gum to LDPE also causes a decrease of its tensile strength. Guar gum is a hydrophilic polymer whereas LDPE is a hydrophobic polymer. Therefore, poor interfacial adhesion properties are expected. Skalkova et al. ${ }^{[20]}$ have used ethylene-acid acrylic copolymer (EAA) as compatibilizer agent for LDPE and LGB blends. This compatibilizer contains groups capable of forming hydrogen bonds with the hydroxyl groups of the galactomannans. They have verified that a finer morphology was obtained with the addition of EAA.

Tensile strength results also show that as the content of LDPE in the ternary blends decreases, the loss of mechanical resistance becomes more accentuated. However, the tensile values of these blends lie in the range of the values presented by some commercial grades of LDPE ${ }^{[22]}$

The elongation at break value of PHB (3.1\%) is much lower than the elongation at break of LDPE (106.4\%). As mentioned before, PHB is a hard and brittle polymer. Therefore, the observed tendency of decrease in elongation at break with increasing concentration of PHB in the blends is justified.

The tensile results indicate that the value of elongation at break of guar gum is higher than the value presented by PHB, but much lower than the value presented by LDPE. 
Table 4. Tensile properties of LDPE/PHB/GG blends.

\begin{tabular}{|c|c|c|c|c|c|c|}
\hline Blends & $\begin{array}{c}\text { Modulus } \\
\text { (MPa) }\end{array}$ & Error & $\begin{array}{c}\text { Tensile } \\
\text { Strength (MPa) }\end{array}$ & Error & $\begin{array}{c}\text { Elongation at } \\
\text { Break (\%) }\end{array}$ & Error \\
\hline PHB (100) & 1030 & 73 & 25.4 & 1.4 & 3.1 & 0.3 \\
\hline LDPE (100) & 102 & 5 & 12.2 & 0.3 & 106.4 & 6.9 \\
\hline LDPE/PHB (70/30) & 281 & 14 & 9.1 & 0.9 & 15.1 & 4.9 \\
\hline LDPE/GG (70/30) & 236 & 7 & 8.1 & 0.1 & 37.8 & 16.0 \\
\hline LDPE/PHB/GG (70/25/5) & 261 & 29 & 8.4 & 0.2 & 21.1 & 2.0 \\
\hline LDPE/PHB/GG (70/20/10) & 228 & 16 & 7.9 & 0.3 & 29.1 & 4.1 \\
\hline LDPE/PHB/GG (70/15/15) & 205 & 11 & 8.9 & 0.6 & 49.7 & 6.4 \\
\hline LDPE/PHB/GG (70/10/20) & 210 & 11 & 8.4 & 0.6 & 40.6 & 3.0 \\
\hline LDPE/PHB/GG (70/5/25) & 221 & 19 & 8.0 & 0.3 & 44.7 & 3.0 \\
\hline
\end{tabular}

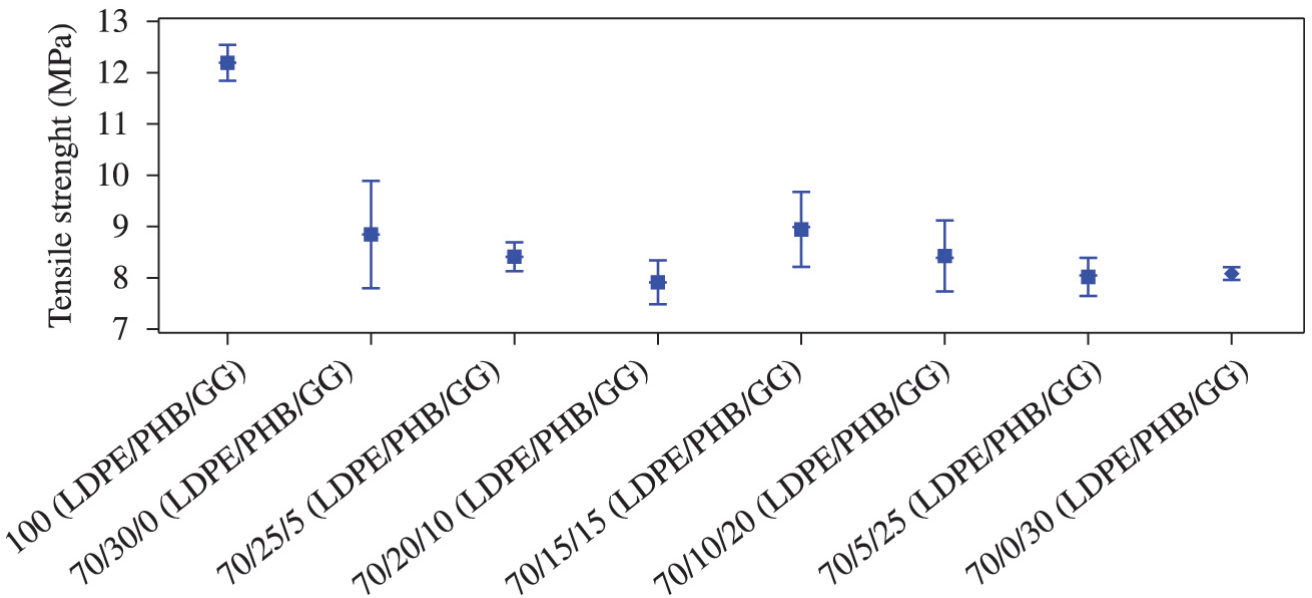

Figure 1. Tensile Strength of the Materials.

The best value of elongation at break, $49.7 \%$, obtained by the $70 / 15 / 15 \mathrm{LDPE} / \mathrm{PHB} / \mathrm{GG}$ blend is low compared to the reported values of elongation at break of LDPE (100-800\%).

Table 5 presents the flexural strength values of LDPE and of LDPE blends. It can be seen that the addition of PHB to LDPE increases the flexural strength of LDPE. This result is in agreement with those obtained by Burlein ${ }^{[6]}$, which demonstrated that the flexural strength of LDPE increases as the content of PHB in the LDPE/PHB blends increases. This result was explained considering the flexural strength value of $\mathrm{PHB}$, which is higher than that presented by LDPE. However, the addition of GG to LDPE provokes a decrease of the flexural strength of LDPE. This result was not expected, as GG is a more rigid material than LDPE. On the other hand, an increase of flexural strength has been observed even in systems with weak adhesion such as HDPE/wood flour composites ${ }^{[23]}$.

Table 5 also shows that the addition of guar gum to LDPE or to LDPE/PHB blends has a negative effect on the flexural strength of the ternary mixtures. Perhaps, the mechanical properties of guar gum in compression are poor. A morphological study should be effect in order to obtain more conclusive results.

The impact properties of the blends may be visualized in Figure 2. Polyethylene sample did not break under
Table 5: Flexural Properties of LDPE/PHB/GG blends

\begin{tabular}{ccc}
\hline Blends & Flexural Strength (MPa) & Error \\
\hline PHB (100) & - & - \\
LDPE (100) & 9.0 & 0.4 \\
LDPE/PHB (70/30) & 14.3 & 1.0 \\
LDPE/GG (70/30) & 6.2 & 0.8 \\
LDPE/PHB/GG (70/25/5) & 7.7 & 0.4 \\
LDPE/PHB/GG (70/20/10) & 7.3 & 0.8 \\
LDPE/PHB/GG (70/15/15) & 6.9 & 0.5 \\
LDPE/PHB/GG (70/10/20) & 7.0 & 0.7 \\
LDPE/PHB/GG (70/5/25) & 6.6 & 0.2 \\
\hline
\end{tabular}

the experimental conditions used in these tests. Both, the addition of PHB or GG to LDPE causes a decrease of impact strength of LDPE, however the effect of PHB on the decrease of the impact properties is higher than the one caused by GG. PHB is a hard and brittle material, so this result was expected. On the other hand, the interfacial adhesion between LDPE and both polymers, PHB and GG is weak. The high impact strength of the $70 / 20 / 10 \mathrm{LDPE} / \mathrm{PHB} / \mathrm{GG}$ was not expected. A morphological study should be conducted in order to elucidate this result. 


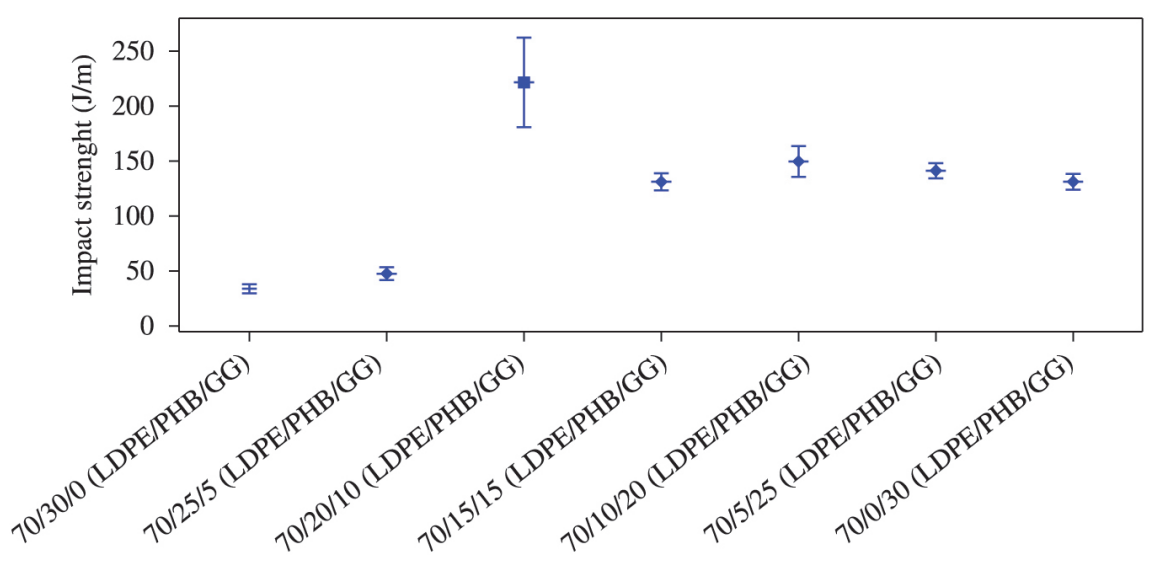

Figure 2. Impact Strength of the Materials.

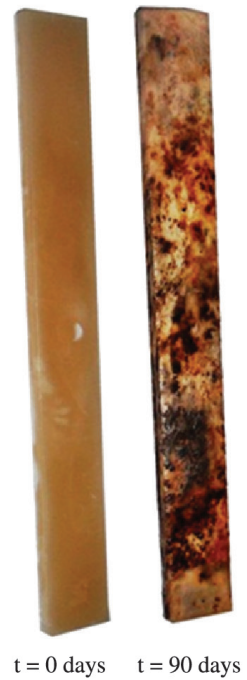

(a)

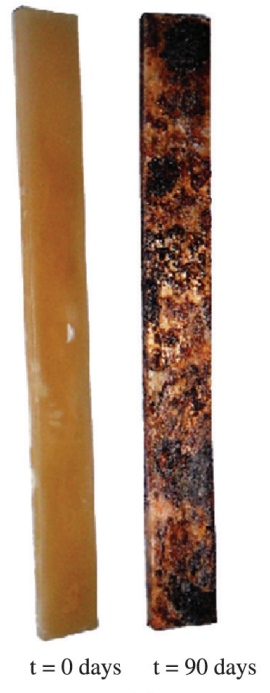

(b)

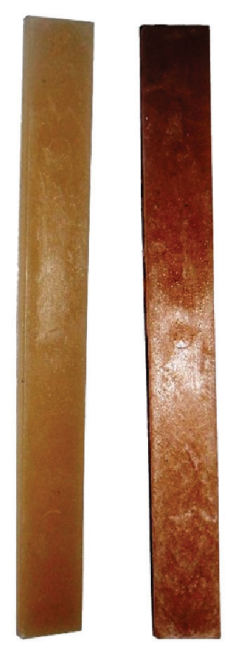

$\mathrm{t}=0$ days $\mathrm{t}=90$ days

(c)

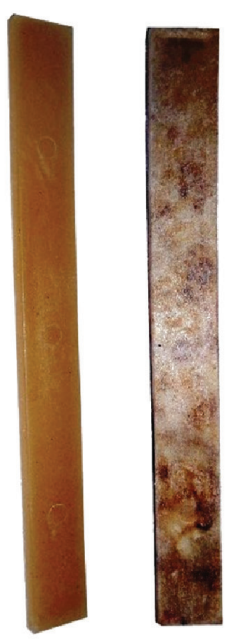

$\mathrm{t}=0$ days $\mathrm{t}=90$ days

(d)

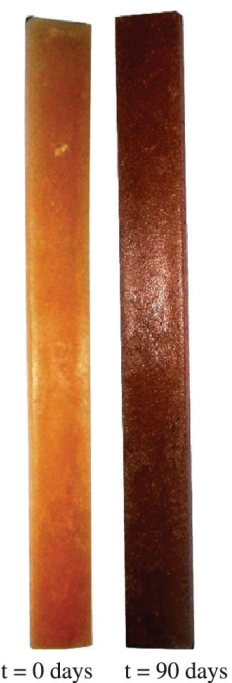

(e)

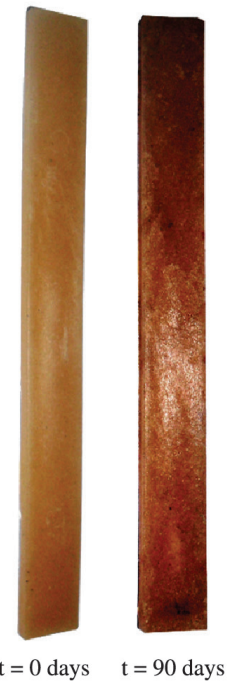

(f)

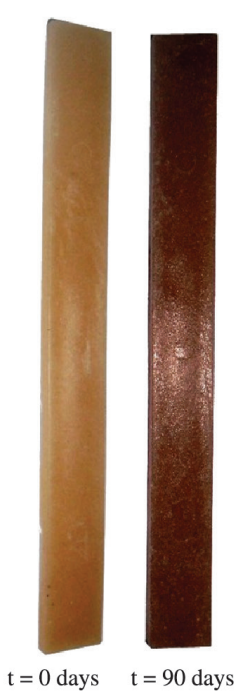

(g)

Figure 3. (a) 70/30/0 (LDPE/PHB/GG) specimem; (b) 70/25/5 (LDPE/PHB/GG) specimem; (c) 70/20/10 (LDPE/PHB/GG) specimen; (d) 70/15/15 (LDPE/PHB/GG) specimen; (e) 70/10/20 (LDPE /PHB/GG) specimen; (f) 70/5/25 (LDPE /PHB/GG) specimen; (g) 70/0/30 (LDPE /PHB/GG) specimen. 
Figures 3a, b, c, d, e, f, g show the visual appearance of the LDPE/PHB/GG specimens after they have been removed from the soil in 90 days. It can be seen that the specimens become clearer as they are degraded. The degradation of LDPE/PHB and LDPE/PHB/GG blends with a content of $\mathrm{PHB}$ equal to or greater than $15 \%$ apparently was more intense than the degradation of samples with low content of PHB. White spots that become larger as the concentration of PHB was increased were observed in a study of biodegradation of LDPE/PHB blends. There was no mention about the source of the spots. Maybe, the cracks and voids give rise to regions with different refractive index that may be responsible by the observed whitening.

The appearance of ternary blends with content lower than $15 \%$ of $\mathrm{PHB}$ presents some darkening, which seems to be independent on the concentration of GG. There are evidences in the literature that a high substitution of mannose units for galactose in galactomannans leads to steric effects that makes easier the dissolution of the polymer in cold water, but avoids the attack of the degrading enzimes ${ }^{[24]}$. Perhaps this fact may explain these preliminary observations of the biodegradation behavior presented by blends with a high content of guar gum.

\section{Conclusions}

The results indicated that in the experimental conditions adopted in this study, LDPE/PHB blends may be used for designing LDPE based materials with increased susceptibility to biodegradation, when elongation at break and impact properties are not determinants factors of their performance. The results also showed that the LDPE/PHB/GG blends exhibit unsatisfactory properties. Apparently, the effect of addition of GG to LDPE on the biodegradation behavior of LDPE/GG blend was less intense than the effect caused by the addition of PHB to the blends. Similar observation has occurred with the partial replacement of GG by PHB in the ternary blends. LDPE/PHB/GG blends exhibit unsatisfactory properties.

\section{References}

1. Hamad, K., Kaseem, M., \& Deri, F. (2011). Melt Rheology of Poly(Lactic Acid)/Low Density Polyethylene Polymer Blends. Advances in Chemical Engineering and Science, 1(4), 208 214. http://dx.doi.org/10.4236/aces.2011.14030.

2. Shah, P. B., Bandopadhyay, S., \& Bellare, J. R. (1995). Environmentally degradable starch filled low density polyethylene. Polymer Degradation \& Stability, 47(2), 165-173. http://dx.doi.org/10.1016/0141-3910(94)00088-P.

3. Chandra, R., \& Rustgi, R. (1998). Biodegradable polymers. Progress in Polymer Science, 23(7), 1273-1335. http://dx.doi. org/10.1016/S0079-6700(97)00039-7.

4. Arvanitotannis, I., Biliaderis, C. G., Ogawa, H., \& Kawasaki, N. (1998). Biodegradable films made from low-density polyethylene (LDPE), rice starch and potato starch for food packaging applications: Part 1. Carbohydrate Polymers, 36(2-3), 89-104. http://dx.doi.org/10.1016/ S0144-8617(98)00016-2.

5. Martelli, S. M., Fernandes, E. G., \& Chiellini, E. (2011). Thermal analysis of soil buried oxo-biodegradable polyethylene based blends. Journal of Thermal Analysis and Calorimetry, 5(3), 333-339.

6. Burlein, G. A. D. (2010). Avaliação das propriedades de polietileno de baixa densidade PEBD, poli (3-hidróxibutirato) (PHB) e de suas misturas com torta de mamona (Master Thesis). State University of Rio de Janeiro, Nova Friburgo.

7. Martelli, S. M. (2011). Environmentally compatible polymeric blends and composites based on oxo-biodegradable polyethylene (Dissertation), University of Pisa, Pisa.

8. Avella, M., Martuscelli, E., \& Raimo, M. (2000). Review Properties of blends and composites based on poly(3-hydroxy) butyrate (PHB) and poly(3-hydroxybutyrate-hydroxyvalerate) (PHBV) copolymers. Journal of Materials Science, 35(3), 523-545. http://dx.doi.org/10.1023/A:1004740522751.

9. Silva, C. R. (2001). Estudo de blendas potencialmente biodegradáveis de poli (3-hidroxibutirato) (PHB) e polietileno de baixa densidade (Master Thesis). University of Campinas, Campinas.

10. Rosa, D. S., Gaboardi, F., Guedes, C. G. F., \& Calil, M. R. (2007). Influence of oxidized polyethylene wax (OPW) on the mechanical, thermal, morphological and biodegradation properties of PHB/LDPE blends. Journal of Materials Science, 42(19), 8093-8100. http://dx.doi.org/10.1007/ s10853-007-1701-z

11. Arkatkar, A., Arutchelvi, J., Sudhakar, M., Bhaduri, S., Uppara, P. V., \& Doble, M. (2009). Approaches to Enhance the Biodegradation of Polyolefins. The Open Environmental Engineering Journal, 2(1), 68-80. http://dx.doi.org/10.2174/ 1874829500902010068.

12. Pankova, Y., Shchegolikhin, A., Iordanskii, A., Zhulkina, A., Ol'Khov, A., \& Zaikov, G. (2011). The characterization of novel biodegradable blends based on polihydroxybutyrate. Chemistry \& Chemical Technology, 5(3), 333-339.

13. Labuzek, S., Nowak, B., \& Pajak, J. (2004). The Susceptibility of Polyethylene Modified with Bionolle to Biodegradation by Filamentous Fungi. Polish Journal of Environmental Studies, 13(1), 59-68.

14. Pinheiro, A. C., Bourbon, A. I., Rocha, C., Ribeiro, C., Maia, J. M., Gonçalves, M. P., Teixeira, J. A., \& Vicente, A. A. (2011). Rheological characterization of $\kappa$-carrageenan/ galactomannan and xanthan/galactomannan gels: Comparison of galactomannans from non-traditional sources with conventional galactomannans. Carbohydrate Polymers, 83(2), 392-399. http://dx.doi.org/10.1016/j.carbpol.2010.07.058.

15 Azero, E. G., \& Andrade, C. T. (1999). Extração e caracterização da galactomanana de sementes de Caesalpinia pulcherrima. Polímeros, 9(2), 54-59.

16 Gupta, A. P., \& Arora, G. (2012). Preperation and Characterization of Cross-linked Guar-Gum Poly(vinylalcohol) Green Films. Der Chimica Sinica, 3(5), 1191-1197.

17 Vendruscolo, C. W. (2005). Goma Xantana e Galactomanana (M. scabrella): Desenvolvimento de matrizes hidrofilicas para liberação modificada de teofilina (Master Thesis). Vale do Itajaí University, Itajaí.

18. Banegas, R. S., Melo, A., \& Soldi, V. (2009). Efeitos do sorbitol e EDC nas propriedades mecânicas e térmicas de filmes formados por goma guar. In Anais da $32^{\mathrm{a}}$ Reunião Anual da Sociedade Brasileira de Química (pp. QC-015). Fortaleza: Sociedade Brasileira de Química.

19. Banegas, R. S., Zornio, C. F., Borges, A. M. G., Porto, L. C., \& Soldi, V. (2013). Preparation, Characterization and Properties of Films Obtained from Cross-linked Guar Gum. Polímeros: Ciência e Tecnologia, 23(2), 182-188.

20 Skalková, P.; Pocarovský, P., \& Durfinová, J. (2011). Thermal and Morphological properties of LDPE/ Galactomannan blends. In P. Skalková, P. Pocarovský, \& J. Durfinová (Eds.), 
Machine Modelling and Simulations (415-420). Trenčín: TnUAD.

21 Rocha, M. C. G., Coutinho, F. M. B., \& Balke, S. (1994). Indice de fluidez: uma variável de controle de processos de degradação controlada de polipropileno por extrusão reativa. Polímeros, 4(3), 33-37.

22. Coutinho, F. M. B., Mello, I. L., \& Santa Maria, L. C. (2003). Polietileno: principais tipos, propriedades e aplicações. Polímeros: Ciência e Tecnologia, 13(1), 1-13.

23. Machado, M. L. C., Pereira, N. C., Miranda, L. F., Terence, M. C., \& Pradella, J. G. C. (2010). Estudo das Propriedades
Mecânicas e Térmicas do Polímero Poli-3-Hidroxibutirato (PHB) e de Compósitos PHB/Pó de Madeira. Polímeros: Ciência e Tecnologia, 20(1), 65-71.

24. Sharma, B. R., Dhuldhoya, N. C., Merchant, S. U., \& Merchant, U. C. (2008). A glimpse of galactomannan. Science Tech Entrepreneur, 1-10.

Received: Jul. 17, 2013

Revised: May 23, 2014

Accepted: Aug. 19, 2014 